\title{
FORENSIC MEDICAL ASSESSMENT \\ OF CERVICAL SPINE TRAUMAS WITH THE ACCOUNT OF CHANGES IN CENTRAL HEMODYNAMICS
}

\author{
Olkhovskiy V. A., Gubin N. V., Peshenko A. N.
}

The article analyzes the up-to-date state and problematic issues of forensic medical diagnosis of cervical spine injuries. It establishes that there are cases when forensic medical experts underestimate the outcomes and consequences of this trauma. It studies the state of the central hemodynamics of the injured with cervical spine traumas. At the same time 107 injured were divided into two groups: with clear and moderate manifestations. The research applied an objective and modern method of Doppler echocardiography. The conducted research has demonstrated significant changes in extra- and intracerebral blood flow. The results of the comparative analysis show that forensic medical assessment of cervical spine traumas should take into account the results of Doppler echocardiography. Among these results the most informative are functional changes of the cerebral and spinal arteries. The manifestation of these deviations is determined, primarily, by the severity and time of injuries. The article determines the ways of improving forensic medical examinations of the injured with cervical spine traumas. It demonstrates the criteria significance of changes in bloodflow of cerebral and cervical arteries of the injured while establishing the severity of injuries.

Keywords: forensic medical assessment, bodily injuries y, cervical spine, cerebral hemodynamics, ultrasound study.

УДК 340.624 .3

I. М. Козаченко, доцент кафедри судовомедичної експертизи Харківської медичної академії післядипломної освіти, кандидат медичних наук, доцент

\section{ВИЗНАЧЕННЯ ВИДУ ПНЕВМАТИЧНОЇ ЗБРОЇ ЗА ДЕЯКИМИ МОРФОЛОГІЧНИМИ ОСОБЛИВОСТЯМИ ВХІДНИХ КУЛЬОВИХ ПОШКОДЖЕНЬ НА ЩІЛЬНИХ ПЕРЕШКОДАХ}

Виконано експериментальні постріли по листам картону із двох пневматичних гвинтівок калібру 4,5 мм із 6-ма й 12-ма правопохилими нарізами каналу ствола кулями шести марок із різною формою головної частини. У результаті пострілів зі зброї з 6-ма нарізами пошкодження мають вигляд правильного шестикутника. Для зброї з 12-ма нарізами характерна форма пошкоджень у вигляді шестерні з відбитками полів нарізів ствола в пояску обтирання кулі. Уперше доведено можливість за морфологічними особливостями кульових пошкоджень на щільних перешкодах визначити кількість нарізів ствола пневматичної зброї.

Ключові слова: пневматична гвинтівка, поля нарізів, головна частина кулі, шестикутник, шестерня, поясок обтирання кулі. 
Промисловості різних країн світу виробляють велику кількість моделей пневматичної зброї (ПЗ), які відрізняються одна від одної за цільовим призначенням, принципом накопичення стисненого повітря (іншого газу), калібром, кількістю й напрямком нарізів каналу ствола, яких може бути від 4 до14. Найбільш поширеними є моделі ПЗ зі стволами, що мають 6 і 12 полів нарізів $^{1}$. Таке розмаїття моделей ПЗ у свою чергу потребує різноманітних снарядів до неї. Серед них переважну більшість складають розширювальні кулі, котрі, зокрема, відрізняються будовою головної частини (ГЧ), яка може бути куполоподібною (domed або roundnose), гострокінцевою (point), пласкою (wadcutter), пласкою з порожниною в центрі або з порожниною та шпильчаком у центрі (hollow point)2.

Спеціального дослідження впливу форми ГЧ на формування вхідних кульових пневмострільних пошкоджень дотепер не проводилося. Однак, слід зазначити, що у двох відомих нам експериментальних роботах, присвячених вивченню пневмострільних пошкоджень, автори виконували постріли із ПЗ кулями з різним типом головної частини (ГЧ). За даними одного з них, що використовував кулі з пласкою, куполоподібною та гострокінцевою ГЧ, пошкодження бавовняної тканини мали неправильну овальну форму й діаметр 3-5 мм. По краях пошкоджень спостерігався поясок обтирання до 0,1 мм завширшки. У центрі пошкоджень були дефекти неправильної овальної форми діаметром від 1 до 4 мм, що залежало від виду кулі. Максимальний за розміром дефект виявився в експериментах із кулями, що мали пласку ГЧ³. Іншим автором при дослідженні вхідних пневмострільних пошкоджень на синтетичній тканині встановлено, що при пострілах кулястим снарядом вони мали круглу форму, при пострілах кулями з куполоподібною та гострокінцевою ГЧ пошкодження були переважно круглими, інколи овальними й подекуди - квадратними. Пошкодження круглої форми були діаметром 4 мм із дефектом діаметром 1 мм. Розміри пошкоджень квадратної форми складали $4 \times 4$ мм із дефектом $1 \times 1$ мм. Пошкодження овальної форми були розмірами $5 \times 4$ мм із дефектом $2 \times 1$ мм. При цьому розміри вхідних пошкоджень практично не відрізнялися від діаметра куль ${ }^{4}$. Отже, існують певні розбіжності в результатах наведених

1 Див.: Козаченко I. М. Класифікація сучасної пневматичної зброї / I. М. Козаченко // Теорія та практика судової експертизи і криміналістики : зб. наук. праць. Х. : Право, 2008. - Вип. 8. - С. 219-224.

2 Див.: Він же. Класифікація снарядів до пневматичної зброї // Там само. - X. : Право, 2009. - Вип. 9. - С. 262-268.

3 Див.: Зеленский С. А. Судебно-медицинская оценка повреждений, причиненных из пневматического оружия различными видами пуль : автореф. дис. на соискание уч. степени канд. мед. наук : спец. 14.00.24 «Судебная медицина» / С. А. Зеленский. М., 2001. - 22 c.

4 Див.: Плетенецька А. О. Судово-медична оцінка ушкоджень тіла людини та одягу, заподіяних при пострілах із потужної пневматичної гвинтівки CROSMAN 2100 CLASSIC (експериментально-морфологічне дослідження) : автореф. дис. на здобуття наук. ступеня канд. мед. наук : спец. 14.01.25 «Судова медицина»/ А. О. Плетенецька. - К., 2012. - 18 с. 
досліджень, зокрема, щодо залежності розмірів дефекту в центрі пошкодження від типу ГЧ кулі.

У практиці бюро судово-медичної експертизи України останнім часом збільшилася кількість експертиз живих осіб, трупів і речових доказів із приводу пневмострільних ушкоджень, заподіяних із сучасних зразків ПЗ великої потужності ${ }^{1}$. Під час виконання таких досліджень експерти вирішують цілу низку питань, серед яких, зокрема, й питання щодо виду зброї та снарядів до неї. Важливим джерелом інформації для вирішення цього завдання слугує вхідне пневмострільне ушкодження на тілі постраждалого, пошкодження на його одязі або інших перешкодах (предметах). У разі пострілу впритул вид П3 можна визначити за особливостями штанцмарки навколо вхідного пошкодження ${ }^{2}$ К Критеріїв, які дозволяють визначити вид ПЗ за морфологічними особливостями вхідного пошкодження за умови відсутності контакту дулового кінця зброї з перешкодою дотепер не виявлено. У той самий час відомо, що при експериментальних пострілах із нарізної вогнепальної зброї зовнішній контур пояска обтирання по краях кульових пошкоджень нерівний має невеликі виступи, які чергуються із невеликими заглибленнями, кількість яких відповідає кількості нарізів у каналі ствола зброї. Ці виступи та заглиблення утворюються внаслідок того, що на боковій поверхні куль, які вистріляна із нарізного ствола, залишаються косі смужки-заглиблення від полів нарізів і смужки-виступи від самих нарізів ${ }^{3}$.

Мета роботи - виявити можливість визначення виду пневматичної зброї та снарядів до неї за формою, розмірами й іншими морфологічними особливостями вхідних кульових пошкоджень на щільних перешкодах.

Для дослідів використовували пружинно-поршневі пневматичні гвинтівки калібру 4,5 мм: Diana-350M (Німеччина) і MP-512 (Росія). Ствол гвинтівки Diana-350M має 12 правопохилих полів нарізів, ствол гвинтівки MP-512 - 6 правопохилих полів нарізів. Також для дослідів відібрано 6 марок розширювальних куль для пневматичної зброї вітчизняних та іноземних виробників калібру 4,5 мм. Кулі поділено на 4 групи, виходячи насамперед із форми їх головної частини (ГЧ). Група № 1 - кулі із куполоподібною ГЧ універсальні (domed або roundnose) - Skarabey DS 0,62 g, а також ковпачкові - Skarabey DS 0,40 g; група № 2 - кулі із пласкою ГЧ

1 Див.: Kozachenko I. M. Fatal airgun shot injuires (based on Forensic Bureau materials) / I. M. Kozachenko // Modern advances in forensic science and expertise : Abstacts of International scientific conference (29 ${ }^{\text {th }}$ of April $-2^{\text {th }}$ of May 2015, Uzhgorod). Ужгород : Вид-во «Бреза А. Е.», 2015. - С. 47-48.

2 Див.: Козаченко I. M. Механізм формування «штанц-марки» на перешкодах при пострілах із пневматичної зброї / І. М. Козаченко // Теорія та практика судової експертизи і криміналістики : зб. наук. праць. - Х. : Право, 2010. - Вип. 10. - С. 310-319.

3 Див. Кривко Ф. П. Установление калибров пуль, вида оружия и некоторых конструктивных признаков канала ствола по входным пулевым повреждениям / Ф. П. Кривко // Первый Всесоюз. съезд суд. медиков : тезисы докл. / под ред. В. М. Смольянинова, Киев, 21-24 сент. 1976 г. — Ставрополь : Ставропольская правда, 1976. - С. 164-165. 
спортивні (wadcutter) - Umarex Match Wc (Німеччина); група № 3 - кулі підвищеної проникності (point) із гострокінцевою ГЧ - «Люман pointed pellets 0,57 г» (Україна) та із ГЧ у формі зрізаного конуса - Rabbit Magnum (Німеччина); група № 4 експансивні (hollow point) із пласкою ГЧ, у центрі якої розташована порожнина з конічним шпильочком - Crosman Destroyer (США).

Як моделі твердих перешкод перед тілом постраждалого, а також якихнебудь твердих і щільних предметів, що могли бути на ньому в мить пострілу (матеріали чи елементи одягу, тверді предмети в кишенях, наприклад, записник, гаманець, різні документи, гаджети та ін.) вибрали листи білого картону 0,45 мм завтовшки, які під час виготовлення з одного боку були покриті сріблястою фольгою 0,05 мм завтовшки. Такий матеріал забезпечив збереження форми й розмірів пошкодження після проходження снаряда, що дало змогу їх подальшого дослідження.

Постріли в зазначені листи картону здійснювали з відстані 1 м для виключення впливу повітря зі ствола зброї на перешкоду під час пострілу. Із кожного зразка зброї виконано 9 серій пострілів по 3 в кожній кулями із перелічених груп. При цьому, з метою забезпечення безпеки й запобігання завдання шкоди зброї, із гвинтівки Diana-350M не виконували пострілів занадто легкими для цієї зброї кулями Skarabey DS 0,40 g (група № 1), a iз гвинтівки MP-512 - кулями Rabbit Magnum (група № 3), оскільки вони занадто важкі для цієї зброї. Замість них використано кулі із тих самих груп 3 аналогічним типом ГЧ: для групи № 1 - кулі Skarabey DS 0,62 g, а для групи № 4 - кулі Crosman Destroyer. Усього виконано 36 залікових опитів.

Отримані мішені досліджували неозброєним оком при природному денному освітленні, а також за допомогою стереомікроскопа МБС-1 при збільшеннях 4,8-56 ${ }^{\times}$. Лінійні виміри куль виконували за допомогою мікрометра із ціною поділки 0,01 мм. Лінійні виміри пошкоджень на мішенях виконували за допомогою окуляр-мікрометра до стереомікроспів із ціною поділки 0,01 мм. На кулях вимірювали максимальні діаметри головної та хвостової частин. У вхідних кульових пошкодженнях вимірювали зовнішній діаметр і діаметр дефекту. Усі об'єкти в процесі дослідження фотографували за правилами судової фотографії цифровою камерою Sony DSC-F707 із використанням спеціальної установки УЛАРУC, а також цифровою камерою до мікроскопів DCM 200. Отримані зображення збережено у вигляді графічних файлів на жорсткому диску компьютера. Під час дослідження отриманих мішеней виявлено, що всі кульові пошкодження на них були наскрізними. Дослідження морфологічних особливостей пошкоджень мішеней показало таке.

Група № 1 - снаряди із куполоподібною ГЧ: пошкодження від куль Skarabey DS 0,40 g, вистріляних із гвинтівки MP-512, мали вигляд дефекту у формі правильного шестикутника із дещо розволокненими краями із світло-сірим пояском обтирання 1-2 мм завширшки, що повторює форму дефек- 
ту (рис. 1a); пошкодження від куль Skarabey DS 0,62 g, вистріляних із гвинтівки Diana-350M, мали вигляд дефекту у формі правильного дрібнозубчастого кола із дещо скошеними розволокненими краями, що в цілому нагадує багатозубу шестірню; навколо країв дефекту спостерігався також фрагментарний світло-сірій поясок обтирання завширшки 1-2 мм, на тлі якого відобразились радіальні вгнуті й опуклі ділянки (рис. $2 a$ ).

Група № 2 - кулі Umarex Match Wc із пласкою ГЧ: пошкодження, що виникли внаслідок пострілів із гвинтівки МР-512, мали вигляд дефекту у формі правильного шестикутника із дещо розволокненими краями (рис. 1б); пошкодження, які виникли внаслідок пострілів із гвинтівки Diana-350M, були у вигляді дефекту у формі правильного зубчастого кола із дещо скошеними розволокненими краями, що в цілому нагадує багатозубу шестірню (рис. 26).

Група № 3 - кулі «Люман pointed pellets 0,57 г» із гострокінцевою ГЧ: пошкодження, які виникли при пострілах із гвинтівок MP-512 та Diana-350M, мали форму кратерів зі скошеними краями, на котрих відобразилися радіальні вгнуті й опуклі ділянки; у центрі цих пошкоджень були дефекти неправильної круглої форми (рис. 16, 26), від яких радіально відходили розриви поверхневих шарів картону довжиною $0,1-0,2$ мм; навколо пошкоджень, що виникли при пострілах із гвинтівки МР-512, відобразився світло-сірий поясок обтирання шестикутної форми (рис. 1в). Пошкодження від куль Rabbit magnum iз ГЧ у формі зрізаного конуса при пострілах із гвинтівки Diana350М відрізнялися від описаних в групі № 3 лише розмірами дефекту в центрі (табл. 2).

Група № 4 - кулі Crosman Destroyer $з$ пласкою ГЧ порожниною та конічним шпильочком у центрі - пошкодження від куль, вистріляних із гвинтівки МР-512, мали вигляд дефекту круглої форми із розволокненими звивистими краями; пошкодження від куль, вистріляних із гвинтівки Diana-350M, мали вигляд дефекту у формі правильного зубчастого кола із дещо скошеними розволокненими краями, що в цілому нагадує багатозубу шестерню.

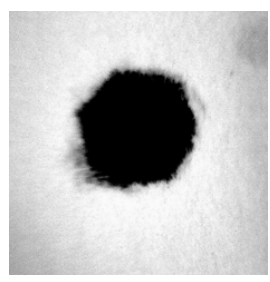

$a$

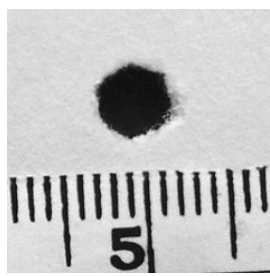

б

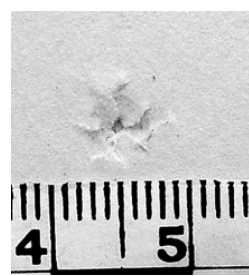

B

Рис. 1. Пошкодження при пострілах із гвинтівки МР-512 кулями з різною формою ГЧ: куполоподібною $(a)$, пласкою (б) й гострокінцевою (в). Шестикутна форма дефектів $(a, \sigma)$ та пояска обтирання $(8)$; на рис. $1 a$ збільшення $8^{\times}$ 


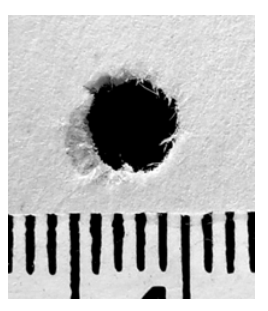

$a$

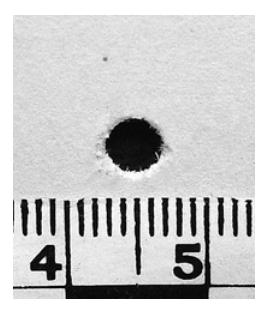

б

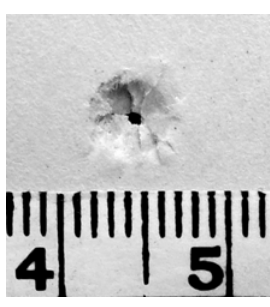

B

Рис. 2. Пошкодження при пострілах із гвинтівки Diana-350M кулями 3 різною формою ГЧ: куполоподібною $(a)$, пласкою (б) й гострокінцевою (в). Зубчаста форма країв пошкоджень із радіальними вгнутими й опуклими ділянками в поясках обтирання

Деякі характеристики застосованих в експериментах куль і особливості вхідних кульових пошкоджень на перешкодах наведено в табл. 1, 2.

Т а бл и ц я 1

Характеристики куль і особливості вхідних кульових пошкоджень (гвинтівка МР-512)

\begin{tabular}{|c|c|c|c|c|c|c|c|}
\hline \multirow{3}{*}{$\begin{array}{l}\text { № } \\
\text { 3/II }\end{array}$} & \multirow{3}{*}{$\begin{array}{l}\text { Марка } \\
\text { кулі }\end{array}$} & \multicolumn{3}{|c|}{ Характеристики куль } & \multicolumn{3}{|c|}{$\begin{array}{c}\text { Особливості кульових } \\
\text { пошкоджень }\end{array}$} \\
\hline & & \multirow[b]{2}{*}{$\begin{array}{c}\text { форма } \\
\text { головної } \\
\text { частини }\end{array}$} & \multicolumn{4}{|c|}{ діаметр } & \multirow[b]{2}{*}{$\begin{array}{c}\text { за- } \\
\text { гальна } \\
\text { форма }\end{array}$} \\
\hline & & & $\begin{array}{c}\text { головної } \\
\text { частини } \\
\text { (мм) }\end{array}$ & $\begin{array}{c}\text { хвостової } \\
\text { частини } \\
\text { (мм) }\end{array}$ & $\begin{array}{l}\text { зовнішній } \\
\text { (мм) }\end{array}$ & $\begin{array}{l}\text { дефекту } \\
\text { (мм) }\end{array}$ & \\
\hline 1 & $\begin{array}{l}\text { Skarabey } \\
\text { DS } 0,40 \mathrm{~g}\end{array}$ & $\begin{array}{l}\text { куполо- } \\
\text { подібна }\end{array}$ & $4,46 \pm 0,06$ & $4,59 \pm 0,01$ & $4,5 \pm 0,1$ & $3,99 \pm 0,08$ & $\begin{array}{l}\text { шести- } \\
\text { кутник }\end{array}$ \\
\hline 2 & $\begin{array}{l}\text { Umarex } \\
\text { Match } \\
\text { Wc }\end{array}$ & пласка & $4,35 \pm 0,02$ & $4,34 \pm 0,01$ & $4,5 \pm 0,01$ & $4,5 \pm 0,01$ & $\begin{array}{l}\text { шести- } \\
\text { кутник }\end{array}$ \\
\hline 3 & $\begin{array}{c}\text { Люман } \\
\text { pointed } \\
\text { pellets } \\
0,57 \text { г }\end{array}$ & $\begin{array}{l}\text { гостро- } \\
\text { кінцева }\end{array}$ & $1,34 \pm 0,01$ & $4,33 \pm 0,01$ & $4,16 \pm 0,06$ & $1,13 \pm 0,06$ & кратер \\
\hline 4 & $\begin{array}{c}\text { Crosman } \\
\text { Destroyer }\end{array}$ & $\begin{array}{c}3 \text { порож- } \\
\text { ниною } \\
\text { та шпи- } \\
\text { льочком } \\
\text { у центрі }\end{array}$ & $4,42 \pm 0,02$ & $4,47 \pm 0,02$ & $4,97 \pm 0,04$ & $4,97 \pm 0,04$ & кругла \\
\hline
\end{tabular}


Та бли ц я 2

Характеристики куль і особливості вхідних кульових пошкоджень (гвинтівка Diana-350M)

\begin{tabular}{|c|c|c|c|c|c|c|c|}
\hline \multirow{3}{*}{$\begin{array}{l}\text { № } \\
\text { 3/II }\end{array}$} & \multirow{3}{*}{$\begin{array}{l}\text { Марка } \\
\text { кулі }\end{array}$} & \multicolumn{3}{|c|}{ Характеристики куль } & \multicolumn{3}{|c|}{$\begin{array}{c}\text { Особливості кульових } \\
\text { пошкоджень }\end{array}$} \\
\hline & & \multirow[b]{2}{*}{$\begin{array}{c}\text { форма } \\
\text { головної } \\
\text { частини }\end{array}$} & \multicolumn{4}{|c|}{ діаметр } & \multirow[b]{2}{*}{$\begin{array}{c}\text { за- } \\
\text { гальна } \\
\text { форма }\end{array}$} \\
\hline & & & $\begin{array}{c}\text { головної } \\
\text { частини } \\
\text { (мм) }\end{array}$ & $\begin{array}{c}\text { хвостової } \\
\text { частини } \\
\text { (мм) }\end{array}$ & $\begin{array}{l}\text { зовнішній } \\
\text { (мм) }\end{array}$ & $\begin{array}{l}\text { дефекту } \\
\text { (мм) }\end{array}$ & \\
\hline 1 & $\begin{array}{l}\text { Skarabey } \\
\text { DS } 0,62 \mathrm{~g}\end{array}$ & $\begin{array}{l}\text { куполо- } \\
\text { подібна }\end{array}$ & $4,41 \pm 0,01$ & $4,46 \pm 0,01$ & $4,9 \pm 0,17$ & $3,95 \pm 0,06$ & зубчаста \\
\hline 2 & $\begin{array}{c}\text { Umarex } \\
\text { Match Wc }\end{array}$ & пласка & $4,35 \pm 0,02$ & $4,34 \pm 0,01$ & $3,99 \pm 0,09$ & $3,99 \pm 0,09$ & зубчаста \\
\hline 3 & $\begin{array}{c}\text { Люман } \\
\text { pointed } \\
\text { pellets } \\
0,57 \text { г }\end{array}$ & $\begin{array}{l}\text { гостро- } \\
\text { кінцева }\end{array}$ & $1,34 \pm 0,01$ & $4,33 \pm 0,01$ & $4,3 \pm 0,15$ & $1,15 \pm 0,03$ & кратер \\
\hline 4 & $\begin{array}{l}\text { Rabbit } \\
\text { Magnum }\end{array}$ & $\begin{array}{l}\text { зрізаний } \\
\text { конус }\end{array}$ & $2,6 \pm 0,17$ & $4,64 \pm 0,01$ & $4,03 \pm 0,11$ & $1,95 \pm 0,08$ & кратер \\
\hline 5 & $\begin{array}{l}\text { Crosman } \\
\text { Destroyer }\end{array}$ & $\begin{array}{c}3 \text { порож- } \\
\text { ниною } \\
\text { та шпи- } \\
\text { льочком } \\
\text { у центрі }\end{array}$ & $4,42 \pm 0,02$ & $4,47 \pm 0,02$ & $4,25 \pm 0,01$ & $4,25 \pm 0,01$ & зубчаста \\
\hline
\end{tabular}

Аналіз наведених у табл. 1, 2 даних свідчить про таке. Розмір дефектів у пошкодженнях, що виникли від пострілів кулями із куполоподібною ГЧ менше ніж діаметр ГЧ таких куль на 0,4-0,5 мм. Розмір дефектів у пошкодженнях, які виникли від пострілів кулями 3 пласкою ГЧ для гвинтівки МР-512 більше діаметра ГЧ таких куль на 0,15-0,2 мм, а в пошкоджень, що виникли від пострілів із гвинтівки Diana-350M - менше діаметра ГЧ на 0,35-0,36 мм. Розмір дефектів у пошкодженнях, які виникли при пострілах кулями із гострокінцевою ГЧ із обох зазначених гвинтівок, менше ніж діаметр ГЧ таких куль на $0,16-0,19$ мм; у той самий час зовнішні діаметри цих пошкоджень практично дорівнюють діаметрам хвостової частини таких куль. Розмір дефектів у пошкодженнях, що виникли при пострілах із гвинтівки Diana-350М кулями із ГЧ у формі зрізаного конуса менше діаметра ГЧ таких куль на 0,4-0,5 мм; зовнішній діаметр пошкоджень менше діаметра хвостової частини цієї кулі на 0,5-0,7 мм. Розмір дефектів у пошкодженнях, які виникли при пострілах кулями експансивної дії із порожниною та шпильочком у центрі порівняно із діаметром ГЧ цих 
куль для гвинтівки MP-512 більше на 0,5-0,55 мм, а для гвинтівки Diana$350 \mathrm{M}$ - менше на 0,17-0,18 мм. Отже, розбіжності в розмірах між пошкодженнями та згаданими частинами куль складають десяті долі міліметра, що не має практичного значення. Дефекти в пошкодженнях на досліджених перешкодах за розмірами відповідають діаметрам ГЧ застосованих куль, від дії яких вони виникли.

Таким чином, результати дослідження дають підстави для таких висновків. При пострілах із пневматичної зброї, що має ствол із 6-ма нарізами від дії розширювальних куль із куполоподібною або пласкою головною частиною на щільних твердих перешкодах формується пошкодження у вигляді шестикутного дефекту, а при пострілах кулями із гострокінцевою головною частиною - шестикутний поясок обтирання, що відповідає кількості полів нарізів ствола. При пострілах із пневматичної зброї, що має ствол із 12-ма нарізами, кулями із куполоподібною або пласкою головною частиною утворюються пошкодження у вигляді дефектів із зубчастими краями та пояском обтирання, у якому відбиваються нарізи каналу ствола. Розміри дефектів у пошкодженнях від дії всіх застосованих куль практично збігаються із розмірами головної частини, а зовнішні розміри пошкоджень від куль із гострокінцевою чи конічною головною частиною - збігаються із діаметром хвостової частини. Отримані результати дослідження дають змогу в певних випадках визначати вид застосованої пневматичної зброї за особливостями вхідних кульових пошкоджень на щільних перешкодах і $є$ перспективними для вирішення цього завдання в разі пневмострільних ушкоджень тіла людини, пошкоджень одягу тощо.

\section{ОПРЕДЕЛЕНИЕ ВИДА ПНЕВМАТИЧЕСКОГО ОРУЖИЯ ПО НЕКОТОРЫМ МОРФОЛОГИЧЕСКИМ ОСОБЕННОСТЯМ ВХОДНЫХ ПУЛЕВЫХ ПОВРЕЖДЕНИЙ НА ПЛОТНЫХ ПРЕПЯТСТВИЯХ}

\section{Козаченко И. Н.}

Выполнены экспериментальные выстрелы по листам картона из двух пневматических винтовок калибра 4,5 мм с 6-ю и 12-ю правонаклонными нарезами канала ствола пулями шести марок с различной формой головной части. В результате выстрелов из оружия с 6-ю нарезами повреждения имеют вид правильного шестиугольника. Для оружия с 12-ю нарезами характерна форма повреждений в виде шестерни с отпечатками полей нарезов ствола в пояске обтирания пули. Впервые доказана возможность по морфологическим особенностям пулевых повреждений на плотных преградах определить количество нарезов ствола пневматического оружия.

Ключевые слова: пневматическая винтовка, поля нарезов, головная часть пули, шестиугольник, шестерня, поясок обтирания пули. 


\section{DETERMINING AIRGUN TYPES \\ FROM MORPHOLOGICAL FEATURES \\ OF INPUT BALL INJURIES ON SOLID OBSTACLES}

\section{Kozachenko I. M.}

Experimental shots were carried out on thin cardboard sheets from two air rifles of sixth and twelfth barrel rifling with expansion bullets of 6 brands having 4 types of head-terms: domed or roundnose, wadcutter, point and hollow point. It was determined that with the shots from rifles MP-512, which has a barrel with sixth rifling, the damage from action from balls with domedor wadcutter-type warhead on solid obstacles had the shape of hexagonal defect, but the shot balls of point type had hexagonal abrasion ring defect, corresponding to the number of barrel rifling. When fired from rifles Diana$350 M$, which has a barrel with twelfth rifling, damage from balls with domed or wadcutter warhead was produced in the shape of defects with serrated edges and an abrasion ring, which reflected the barrel rifling that generally resembles pinion teeth. Defect sizes in damages from all applied balls practically coincide with the size of the warhead and external dimension injuries from bullets with pointed warhead match the diameter of the shafting balls. For the first time the possibility of determining the number of rifling in the barrel by means of morphological features of bullet injuries from airguns on solid obstacles is proved.

Keywords: air rifle, rifling fields, the main part of the globe, hexagon, gear, abrasion ring.

УДК: 340.624 .3

B. В. Щербак, асистент кафедри судовомедичної експертизи Харківської медичної академії післядипломної освіти

\section{ВИЗНАЧЕННЯ ХАРАКТЕРИСТИК ТИМЧАСОВОЇ ПУЛЬСУЮЧОЇ ПОРОЖНИНИ ПРИ ПОСТРІЛАХ ІЗ ПІСТОЛЕТА «ФОРТ-12»}

Досліджено морфологічні особливості формування тимчасової пульсуючої порожнини в експерименті на балістичному желатині як еквіваленті пошкоджувальної дії вогнепального снаряду при пострілах із пістолета «Форт-12».

Ключові слова: вогнепальні пошкодження, ранова балістика, балістичний желатин, імітатор тканин людини, пістолет «Форт-12».

Дослідження закономірностей формування тимчасової пульсуючої порожнини (ТПП) у біологічних тканинах є однією з провідних проблем ранової балістики. Питання про час виникнення тимчасової порожнини, характер пульсацій, залежність між розмірами порожнини, кінетичною

(C) Щербак В. В., 2015 